\title{
Anticandidal effect of endophytic bacteria isolated from Equisetum arvense $L$. against Candida albicans and Candida glabrata
}

\author{
Gitishree Das ${ }^{1}$, Jayanta Kumar Patra ${ }^{1}$, Jaehyuk Choi ${ }^{2}$, Kwang-Hyun Baek ${ }^{2 *}$. \\ ${ }^{I}$ Dongguk University - Seoul, Research Institute of Biotchnology \& Medical Converged Science,, Goyang-si, South \\ Korea; ${ }^{2}$ Yeungnam University, Department of Biotechnology, Gyeongsan, South Korea.
}

\begin{abstract}
Equisetum arvense, a fern species possesses a number of pharmaceutical prospective. In the present study, a total of 103 endophytic bacteria isolated from $\mathrm{E}$. arvense and were evaluated for their anticandidal property against five Candida species, two C. albicans, C. glabrata, C. saitoana and C. geochares. Out of them fifty one were identified as per the morphological and molecular characterisation using 16S rRNA gene sequencing and among them, ten promising endophytic bacteria were mentioned in the present study. Among ten endophytic bacteria, Psychrobacillus insolitus and Curtobacterium oceanosedimentum exerted highest anticandidal effect against $\mathrm{C}$. albicans KACC 30062 and C. glabrata KBNO6P00368, with diameter of inhibition zones of 24.07 \pm 0.74 and $18.24 \pm 0.12 \mathrm{~mm}$, respectively. When the endophytic bacteria cultures were successively fractionated using different solvents, only the butanol fraction of Psychrobacillus insolitus and Curtobacterium oceanosedimentum had anticandidal activity, with inhibition zones of $20.12 \pm 0.28 \mathrm{~mm}$ and $12.33 \pm 0.11 \mathrm{~mm}$, respectively. The minimum inhibitory concentration (MIC) and minimum fungicidal concentration (MFC) values of the butanol fractions ranged from 250 to 500 and 500 to $1,000 \mu \mathrm{g} / \mathrm{mL}$, respectively. Scanning electron microscope (SEM) analysis showed impaired membrane of $\mathrm{C}$. albicans and $\mathrm{C}$. glabrata at the MIC, indicating that butanol extract lysed the cell membrane and caused cell death. The endophytic bacteria derived from E. arvense can be a valuable resource for the development of natural anticandidal agents to manage candidiasis.
\end{abstract}

Key words: Anticandidal effect, endophytic bacteria, Equisetum arvense, Candida albicans, Candida glabrata.

\footnotetext{
*Author for correspondence: khbaek@ynu.ac.kr
} 
Das, $\mathrm{G}$ et al.

\section{INTRODUCTION}

The occurrence of persistent fungal infections is mainly caused by opportunistic fungi of the genus Candida ${ }^{1}$. More than 17 diverse Candida species are well-known etiological agents of human illness, while more than $90 \%$ of persistent infections are caused by $C$. albicans and $C$. glabrata ${ }^{2-4}$. As a frequent source of systemic mycoses, C. albicans can colonize both external and internal surfaces on common healthy individuals. Indeed, it can produce a wide spectrum of diseases such as Candida peritonitis, systemic candidiasis and hepatosplenic ${ }^{5,6}$. Despite modern management options, mortality rates due to fungal infection are in the front-line for C. glabrata infection. It is believed that $C$. glabrata emerged as a human pathogen from additional Candida species ${ }^{7}$. Leading cause of disseminated candidiasis is due to $C$. glabrata. Overall, the mortality rate is around $40 \%^{8-10}$ and in some series it is related to worse health outcomes than occurs in response to infection by other Candida species ${ }^{11}$. Persistent infections caused by C. glabrata in neutropenic patients are a severe, but relatively rare clinical syndrome, accounting for just about $5 \%$ of the overall number of invasive cases ${ }^{9,10,12}$.

Candida infections are gaining greater attention due to more use of broad spectrum antibiotics and immunosuppressive agents and it is the main cause of death and a great threat to the hospitalized patients. Thus, the activities seeking to get the novel anticandidal compounds, especially from natural sources are very high ${ }^{11}$. Owing to the increasing occurrence of Candida infections in immuno-compromised patients, there is an urgent demand for anticandidal drugs. The frequencies of candidiasis have grown by ten-fold in the last two decades ${ }^{11}$. Currently, there is an urgent requirement for novel beneficial agents that can support the antifungal activity ${ }^{13}$. The use of antifungals and resistance of Candida infections to drugs have been increasing gradually, and a serious concern globally ${ }^{13,14}$.

Endophytic bacteria (EB) can be a prospective biological control agent against various fungal diseases ${ }^{15,16}$. There is report of EB isolated from medicinal plant Phyllanthus niruri having anticandidal activity against $C$. albicans ${ }^{17}$. Recently, Bacillus isolated from soil has been shown to have anticandidal activity, while EB isolated from various plant species were found to have antimicrobial activities ${ }^{16,18,19}$. Antimicrobial potentials were reported for EB isolated from the medicinal plants Phyllodium pulchellum (Benth) Desv, Tinospora cordifolia Miers, Memecylon edule Roxb and Dipterocarpus tuberculatus Roxb ${ }^{20}$. The anticandidal potential of EB depends highly on their genotype and chemical compositions.

Equisetum arvense, one of the oldest fern plants, belongs to the family Equisetaceae. This plant is known as a rich source of many useful natural compounds, including saponins, triterpenoids, phytosterols, alkaloids, flavonoids and minerals. E. arvense is well-known for its large therapeutic potential and its antioxidant and antimicrobial activity $^{21-23}$. Additionally, $E$. arvense extract has been used in traditional medicine for the treatment of various health conditions, including as an astringent for tissue healing and for curing of kidney stones. The herbal extracts of $E$. arvense L. possess antimicrobial, anti-inflammatory and anticancer effects ${ }^{24-30}$. The essential oil of $E$. arvense exerted antibacterial and anticandidal potentials ${ }^{31-33}$. To date, 25 compounds with antimicrobial activities have been identified in essential oil obtained from the aerial parts of the plant ${ }^{25,35}$. Moreover, the extract of $E$. arvense L. at a concentration of $50 \mathrm{mg} / \mathrm{mL}$ was found to be $100 \%$ effective against C. albicans and C. glabrata $^{26}$. There are also reports of propylene glycol extract of $E$. arvense and mixture of extract and formulated gel having anticandidal and antibacterial activity ${ }^{36}$. The ethyl acetate extract of another species of Equisetum (E. giganteum) contained a clear presence of phenolic compounds and exerted antimicrobial activity against $C$. albicans $^{37}$. 
Endophytic bacteria are capable of producing bioactive compounds in favour of diverse biotechnological appliances. However, no studies have reported the isolation of endophytic bacteria from $E$. arvense or evaluated the anticandidal activities of the associated bacteria. Therefore, we isolated the endophytic bacteria from $E$. arvense and evaluated their effects against five different Candida species.

\section{MATERIAL AND METHODS}

\section{ISOLATION OF ENDOPHYTIC BACTERIA}

The fern, E. arvense (Figure 1), was collected from three different locations at the campus of Yeungnam University in 2014 (Gyeongsan, Republic of Korea), after which the endophytic bacteria were isolated by standard isolation protocol ${ }^{38}$. Briefly, 2 grams of the leaves, stems and roots of $E$. arvense were washed with running tap water, sterilized with $70 \%$ ethanol for $60 \mathrm{sec}, 2 \%$ sodium hypochlorite for $90 \mathrm{sec}$ and $100 \%$ ethanol for $30 \mathrm{sec}$, consecutively, and then washed five times with sterile $\mathrm{ddH}_{2} \mathrm{O}$. After being dried with sterilized blotting sheets, the tissues were ground with a sterilized mortar and pestle. Next, $6 \mathrm{~mL}$ of $0.9 \% \mathrm{NaCl}$ solution was added and the samples were incubated for $3 \mathrm{~h}$ at room temperature. The supernatant was then diluted 100 times with $0.9 \% \mathrm{NaCl}$, after which $100 \mu \mathrm{l}$ aliquots of the diluted extracts were spread on YNA media (yeast extract $5 \mathrm{~g}$, nutrient broth $8 \mathrm{~g}$ and agar $15 \mathrm{~g} /$ liter) in triplicate for each dilution. Samples were then incubated for 15 days at $28^{\circ} \mathrm{C}$, after which the total colonies were counted and expressed in colony forming units (CFUs)/g of tissue. The morphology was characterized based on color, form, elevation, margin and size of the endophytic bacteria colony according to standard procedures $^{39,40}$.

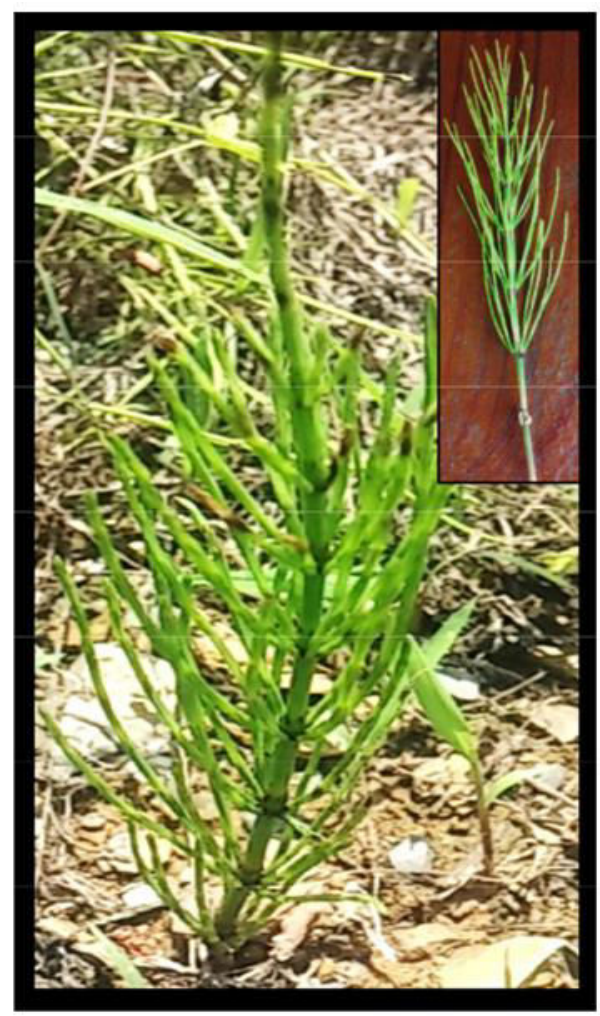

Figure 1: Photograph of fern plant Equisetum arvense. 


\section{ANTICANDIDAL SCREENING}

The five pathogenic Candida strains used in this study were $C$. albicans KACC 30003 and C. albicans KACC 30062, C. saitoana KACC 41238 and C. geochares KACC 30061 obtained from the KACC (Korean Agricultural Culture Collection, Suwon, Republic of Korea). C. glabrata KBNO6P00368 was obtained from Chonbuk National University Hospital (Cheongju, Republic of Korea).

The EB from E. arvense were screened for their anticandidal activity against the five Candida species as previously described, with slight modification ${ }^{18}$. Briefly, Candida species were grown for $24 \mathrm{~h}$ at $28^{\circ} \mathrm{C}$ in potato dextrose broth (PDB, Becton, Dickinson and Company, MD,USA). Next, $10 \mu$ of the overnight grown culture $\left(\mathrm{OD}_{600}=1.0\right)$ of EB was dropped slowly onto the YNA Petri plates (Becton, Dickinson and Company, MD, USA), allowed to dry for $10 \mathrm{~min}$, then incubated at $28^{\circ} \mathrm{C}$ for $24 \mathrm{~h}$. The grown patches of EB were subsequently killed by adding 1,000 $\mu \mathrm{l}$ chloroform to the lids of Petri plates, then inverting the plates and allowing them to stand for $10 \mathrm{~min}$ on a laminar floor hood. Next, the lids were removed and the open Petri plates were allowed to stand for $30 \mathrm{~min}$ inside the laminar floor hood to remove traces of chloroform. The Petri plates in the clean bench were subsequently treated with UV light for 15 min to kill the bacteria completely. Next, $35 \mu \mathrm{l}$ of freshly grown Candida culture $\left(\mathrm{OD}_{600}=1.0\right)$ were suspended in $10 \mathrm{~mL}$ of PDA $(0.75$ $\%$ agar) at $55^{\circ} \mathrm{C}$, then poured over the killed bacteria patches. After solidification, the Petri plates were incubated at $28^{\circ} \mathrm{C}$ for $24 \mathrm{~h}$, after which the diameter of the zone of inhibition was measured using an electronic digital calliper (M500-182M, Konex, Tool Parts Company, Republic of Korea). All experiments were repeated three times.

\section{FRACTIONATION USING SOLVENT FROM ENDOPHYTIC BACTERIA}

The metabolites from EB were fractionated successively in the different polarity based solvents, n-hexane, chloroform, ethyl acetate and butanol, following standard protocols, with slight modification ${ }^{41}$. Briefly, EB were grown in $200 \mathrm{~mL}$ of YNB (yeast extract and nutrient broth, Becton, Dickinson and Company, MD, USA) at $28^{\circ} \mathrm{C}$ for 4 days. After incubation, the cultures were mixed with an equal volume of $\mathrm{n}$-hexane and sonicated for $10 \mathrm{~min}$, then fractionated overnight. After removing the hexane fraction using a separating funnel, an equal volume of chloroform was added to the residual solution and the sample was fractionated overnight. The chloroform fraction was then separated and dried in rotary evaporator, after which the residual culture was mixed with an equal volume of ethyl acetate and the ethyl acetate fraction was separated and dried. Finally, the residual culture was mixed with an equal volume of $\mathrm{n}$ - butanol and the butanol fraction was separated and dried.

\section{ANTICANDIDAL ACTIVITY OF SOLVENT EXTRACT}

The anticandidal activities of different solvent extracts (n-hexane, chloroform, ethyl acetate and butanol) of two EB, $P$. insolitus and $C$. oceanosedimentum, were premeasured by the standard disc diffusion method ${ }^{42}$. Prior to analysis, sterilized $8 \mathrm{~mm}$ paper discs (Advantec, Toyo Roshi Kaisha, Ltd., Japan) were prepared by adding $50 \mu \mathrm{l}$ of the solvent extracts $(500 \mu \mathrm{g} / \mathrm{disc})$. Next, $35 \mu \mathrm{l}$ of freshly grown Candida culture $\left(\mathrm{OD}_{600}=1.0\right)$ were mixed in $10 \mathrm{~mL}$ of PDA $(0.75 \%$ agar $)$ at $55^{\circ} \mathrm{C}$ and poured over PDA (1.5\% agar) Petri plates. After solidification of the Petri plates, sterilized paper discs with solvent extract were placed on the plates and samples were incubated at $28^{\circ} \mathrm{C}$ for $24 \mathrm{~h}$. Amphotericin b $(10 \mu \mathrm{g} / \mathrm{disc})$ was taken as the positive control and 5\% DMSO was taken as the negative control. The diameter of the zone of inhibition was then measured using an electronic digital calliper (M500182M, Konex, Tool Parts Company, Republic of Korea). 


\section{EVALUATION OF MIC AND MFC OF SOLVENT EXTRACT}

The butanol fractions of the two selected EB $P$. insolitus and $C$. oceanosedimentum were evaluated for MIC and MFC against $C$ albicans KACC 30062 and $C$ glabrata KBNO6P00368 by two-fold dilution method, with minor modifications ${ }^{43}$. The lowest concentration of the butanol fraction that showed no visible growth of the tested pathogenic Candida on liquid culture was taken as the minimum inhibitory concentration. The lowest concentration of the butanol fraction that did not show any growth of Candida colony on the PDA plates was selected as the minimum fungicidal concentration. The MIC and MFC values were expressed in $\mu \mathrm{g} / \mathrm{mL}$.

\section{IDENTIFICATION OF ENDOPHYTIC BACTERIA USING 16S RRNA SEQUENCING AND PHYLOGENETIC ANALYSIS}

The ten promising EB isolated from $E$. arvense were identified through $16 \mathrm{~S}$ rRNA gene sequencing by ABI Prism 3730xl DNA sequencer (Geno Tech, 26-69, Gajeongbuk-ro, Yuseong-gu, Daejeon, Republic of Korea 305-343).The sequencing results of the identified EB isolated from E. arvense were aligned and the phylogenetic tree construction was done by using MEGA6 software (version 6). Determination of the phylogenetic trees was done by the neighbor joining method ${ }^{44}$. The significant tree topology was esteemed by bootstrap analyses, based on the neighbor-joining method (1000 replicates).

\section{SEM ANALYSIS}

The effects of the butanol fraction of two selected EB on the morphology of $C$ albicans KACC 30062 and $C$ glabrata KBNO6P00368 were evaluated by SEM. For sample preparation, two sets of vials containing $890 \mu$ PDB media were prepared. A total of $100 \mu \mathrm{l}$ of $5 \%$ DMSO (control) or $100 \mu \mathrm{l}$ of MIC of the butanol fraction of $P$. insolitus and $C$. oceanosedimentum were added to each set. Next, $10 \mu \mathrm{l}$ of fresh culture of Candida species grown for $24 \mathrm{~h}$ at $28^{\circ} \mathrm{C}$ was added to both the control and treatment vials, after which samples were incubated for $24 \mathrm{~h}$ at $28^{\circ} \mathrm{C}$. After centrifuging the control and treatment vials at $1,000 \times \mathrm{g}$ for $10 \mathrm{~min}$, the pellets were collected and washed with $100 \mu \mathrm{l}$ phosphate buffer solution (0.05 M, pH7.4) three times. A Candida smear was then prepared on a glass slide using a wire loop, dried, covered with $200 \mu \mathrm{l}$ of $2.5 \%$ glutaraldehyde, and incubated for $2 \mathrm{~h}$ at room temperature. Next, the smear was washed with $0.05 \mathrm{M}$ phosphate buffer solution for $1 \mathrm{~min}$, then dehydrated successively with $50 \%$ ethanol (20 min), $70 \%$ ethanol (20 $\mathrm{min}), 80 \%$ ethanol (20 $\mathrm{min}), 90 \%$ ethanol (20 $\mathrm{min}), 95 \%$ ethanol (20 min) and $100 \%$ ethanol (20 min), after which $200 \mu \mathrm{l}$ of t-butanol was added and the sample was incubated for $2 \mathrm{~h}$ at room temperature. The t-butanol over the smear was then discarded, and the smear was again added with $200 \mu \mathrm{l}$ of fresh t-butanol, and stored at $-20^{\circ} \mathrm{C}$ till further use ${ }^{45}$. For SEM analysis, the specimens were sputter-coated with platinum using an ion coater for 2 min immediately before analysis, after which they were subjected to scanning electron microscopy (S-4100, Hitachi, Japan).

\section{STATISTICAL ANALYSIS}

Samples were analyzed by one way ANOVA and Duncan's multiple range tests, with a $P<0.05$ taken to indicate significance. All results were expressed as the mean \pm standard deviation. SAS 9.4 version (SAS Inc., Cary, USA) was used for all analyses. 


\section{RESULTS}

\section{ISOLATION AND IDENTIFICATION OF ENDOPHYTIC BACTERIA ISOLATED FROM E. arvense USING 16S rRNA SEQUENCING}

Among 103 EB isolated from E. arvense (Figure 1), fifty one were identified according to the morphological characters, using $16 \mathrm{~S}$ rRNA gene sequencing and ten exerted anticandidal activities against three Candida species, $C$. albicans KACC 30003, C. albicans KACC 30062 and C. glabrata KBNO6P00368 were mentioned in our present study (Table 1). The EB were identified as Arthrobacter oxydans (EAL16), Bacillus thuringiensis (EAS29), Pantoea agglomerans (EAS30), Psychrobacillus insolitus (EAL86), B. anthracis (EAS101), B. mycoides (EAS111), B. cereus (EAS112), Curtobacterium oceanosedimentum (EAL157), B. weihenstephanensis (EAL159) and Staphylococcus capitis subsp. ureolyticus (EAL160). The morphology and characterization of the bacteria (Figure 2) are summarized in Table 1.

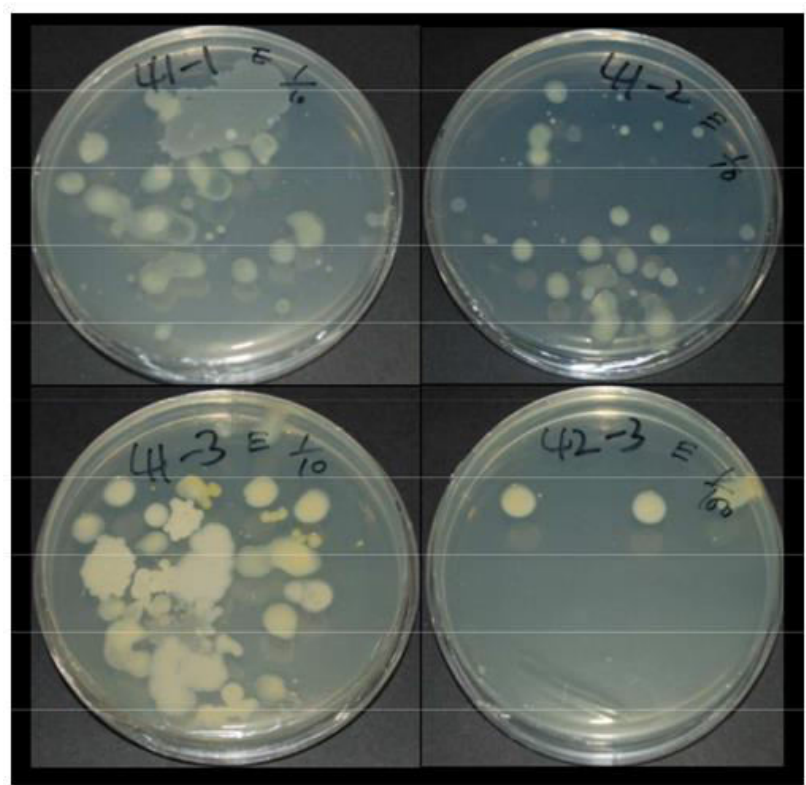

Figure 2: Morphology of endophytic bacteria isolated from Equisetum arvense

TABLE 1: Colony morphology and molecular identification of endophytic bacteria (EB) isolates from Equisetum arvense.

EB Tissue source Color Form Size Closest relative Max. score E. value identity

\begin{tabular}{lcccccccc}
\hline EAL16 & Leaf & P. Yellow & Round & Medium & A. oxydans & 2752 & 0 & $99 \%$ \\
EAS 29 & Stem/Root & White & Irregular & Large & B. thuringiensis & 2861 & 0 & $100 \%$ \\
EAS 30 & Stem/Root & White & Round & Small & P. agglomerans & 2744 & 0 & $99 \%$ \\
EAL86 & Leaf & Transparent & Round & Small & P. insolitus & 2706 & 0 & $98 \%$ \\
EAS101 & Stem/Root & F. Green & Round & Medium & B. anthracis & 2849 & 0 & $99 \%$ \\
EAS111 & Stem/Root & F. Green & Round & Small & B. mycoides & 2787 & 0 & $99 \%$ \\
EAS112 & Stem/Root & White & Round & Small & $\begin{array}{c}\text { B. cereus } \\
\text { S. }\end{array}$ & 2773 & 0 & $99 \%$ \\
EAL157 & Leaf & White & Round & Medium & oceanosedimentum & 2662 & 0 & $99 \%$
\end{tabular}


Anticandidal effect of Equisetum arvense

\begin{tabular}{|c|c|c|c|c|c|c|c|c|}
\hline EAL159 & Leaf & White & Irregular & Medium & $\begin{array}{c}B . \\
\text { weihenstephanensi } \\
S\end{array}$ & 2789 & 0 & $99 \%$ \\
\hline EAL160 & Leaf & White & Round & Small & $\begin{array}{c}S . \\
\text { capitis.ureolyticus }\end{array}$ & 2214 & 0 & $95 \%$ \\
\hline
\end{tabular}

F. Green: Fluorescent green; P. Yellow: Pale Yellow

\section{ANTICANDIDAL PROSPECTIVE FOR ENDOPHYTIC BACTERIA ISOLATED FROM $E$. arvense}

The EB isolated from $E$. arvense were screened for their anticandidal activity against five Candida species, C. albicans KACC 30003 and C. albicans KACC 30062, C. glabrata KBNO6P00368, C. saitoana KACC 41238 and C. geochares KACC30061. Ten EB exerted anticandidal activity against three Candida sp. Two endophytic bacteria, B. weihenstephanensis and S. capitis subsp. ureolyticus, showed anticandidal effects against $C$. albicans KACC 30003 with inhibition zones of $10.03 \pm 0.01 \mathrm{~mm}$ and $10.08 \pm 0.03 \mathrm{~mm}$, respectively. Seven EB, A. oxydans, B. thuringiensis, $P$. agglomerans, $P$. insolitus, B. anthracis, B. mycoides and B. cereus, showed positive activity against $C$. albicans KACC 30062 with inhibition zones of $21.30 \pm 0.41 \mathrm{~mm}, 13.58 \pm 0.43 \mathrm{~mm}, 10.96 \pm 0.15 \mathrm{~mm}, 24.07 \pm 0.74 \mathrm{~mm}, 9.76 \pm 0.08 \mathrm{~mm}$, $10.93 \pm 0.52 \mathrm{~mm}$ and $10.48 \pm 0.12 \mathrm{~mm}$, respectively. Only one $\mathrm{EB}, C$. oceanosedimentum, showed strong anticandidal activity, with an inhibition zone of 18.24 \pm 0.12 against $C$. glabrata KBNO6P00368 (Figure 3, Table 2). Among the EB, $P$. insolitus and $C$. oceanosedimentum showed the highest inhibition against $C$. albicans KACC 30062 and C. glabrata KBNO6P00368, respectively (Figure 3, Table 2). Out of the ten EB, five were isolated from stems/roots and five were from leaf tissues of E. arvense (Table 1). All five identified Bacillus species were only isolated from stem/root tissues.

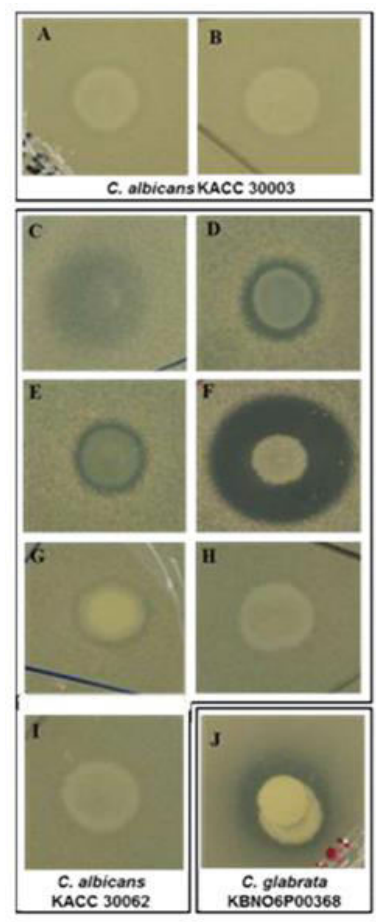

Figure 3: Anticandidal potential of endophytic bacteria against pathogenic candida species. (A) $B$. weihenstephanensis and (B) S. ureolyticus against C. albicans KACC 30003, (C) A. oxydans, (D) B. thuringiensis, (E) P. agglomerans, (F) P. insolitus, (G) B. anthracis, (H) B. mycoides (I) B. cereus against C. albicans KACC 30062 and (J) C. oceanosedimentum against $C$. glabrata KBNO6P00368. 
TABLE 2: Anticandidal potential of endophytic bacteria (EB) isolated from Equisetum arvense against Candida species.

\begin{tabular}{lccc}
\multicolumn{3}{c}{ Inhibition zone* } \\
\multicolumn{1}{c}{ EB } & C. albicans & C. albicans & C. glabrata \\
& KACC 30003 & KACC 30062 & KBNO6P00368 \\
\hline B. weihenstephanensis & $10.03 \pm 0.01^{\mathrm{fg} * *}$ & - & \\
S. capitis ureolyticus & $10.08 \pm 0.03^{\mathrm{fg}}$ & - & - \\
A. oxydans & - & $21.30 \pm 0.41^{\mathrm{b}}$ & - \\
B. thuringiensis & - & $13.58 \pm 0.43^{\mathrm{d}}$ & - \\
$P$. agglomerans & - & $10.96 \pm 0.15^{\mathrm{e}}$ & - \\
$P$. insolitus & - & $24.07 \pm 0.74^{\mathrm{a}}$ & - \\
B. anthracis & - & $9.76 \pm 0.08^{\mathrm{g}}$ & - \\
B. mycoides & - & $10.93 \pm 0.52^{\mathrm{e}}$ & - \\
B. cereus & - & $10.48 \pm 0.12^{\mathrm{ef}}$ & $18.24 \pm 0.12^{\mathrm{c}}$ \\
C. oceanosedimentum & - & - & \\
\hline
\end{tabular}

$*$ Diameter of zone of inhibition is expressed as mean \pm SD in $\mathrm{mm}$.

**Different superscript letters represents significant differences at $P<0.05$

\section{ANTICANDIDAL ACTIVITY OF SOLVENT EXTRACT}

From the primary anticandidal screening, the two EB with the highest anticandidal effects, $P$. insolitus and $C$. oceanosedimentum, were selected for further fractionation using n-hexane, chloroform, ethyl acetate and n-butanol. The n-hexane, chloroform and ethyl acetate extracts of $P$. insolitus and $C$. oceanosedimentum did not show any inhibitory activity against any Candida species. The yield of the butanol extract was $0.0195 \mathrm{~g}$ and $0.007 \mathrm{~g}$ of extract per $200 \mathrm{~mL}$ of $P$. insolitus and $C$. oceanosedimentum culture, respectively. The butanol fraction of $P$. insolitus showed anticandidal effects, with an inhibition zone of $20.12 \pm 0.28 \mathrm{~mm}$ against $C$. albicans, whereas that of $C$. oceanosedimentum showed an inhibition zone of $12.33 \pm 0.11 \mathrm{~mm}$ against $C$.

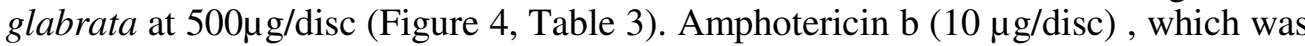
taken as the positive control exhibited 12.61 and $11.07 \mathrm{~mm}$ inhibition zones against both the Candida species respectively (Table 3). DMSO which was taken as the positive control did not exhibit any positive response against both the Candida species.
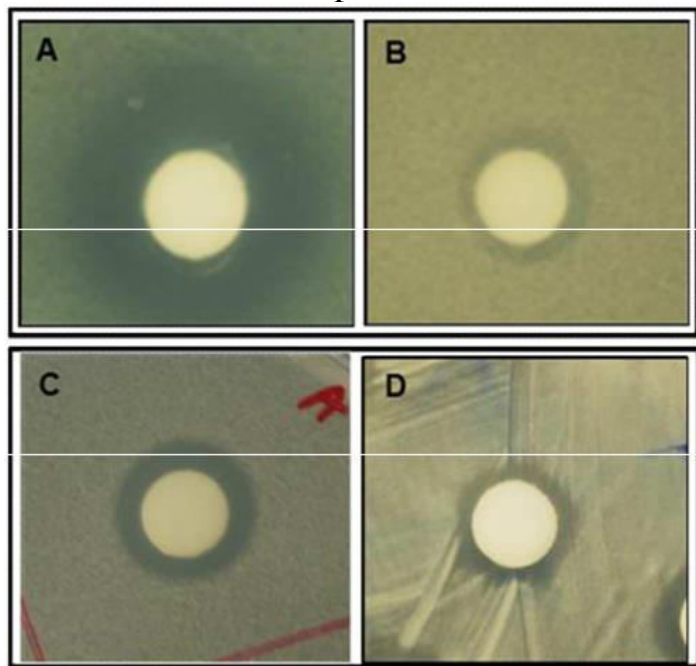

Figure 4: Anticandidal potential of butanol fraction of $P$. insolitus against $C$. albicans KACC 30062 (A); $C$. oceanosedimentum against C. glabrata KBNO6P00368 (B); Amphotericin B against C. albicans KACC 30062 (C) and Amphotericin B against C. glabrata KBNO6P00368 (D). 
TABLE 3: Anticandidal potential of the butanol fraction $(500 \mu \mathrm{g} / \mathrm{disc})$ of endophytic bacteria (EB) isolated from Equisetum arvense and its MIC and MFC values and standard Amphotericin B (10 $\mu \mathrm{g} / \mathrm{disc})$ against two Candida species

\begin{tabular}{lcccc}
\multicolumn{1}{c}{ EB } & C. albicans & C. glabrata & \\
& KACC 30062 & KBNO6P00368 & MIC $(\mu \mathrm{g} / \mathrm{mL})$ & MFC $(\mu \mathrm{g} / \mathrm{mL})$ \\
\hline & $20.12 \pm 0.28 *$ & - & 250 & 500 \\
$P$. insolitus & - & $12.33 \pm 0.11$ & 500 & 1,000 \\
$\begin{array}{l}\text { C. oceanosedimentum } \\
\text { Amphotericin B }\end{array}$ & $12.61 \pm 0.35$ & $11.07 \pm 0.57$ & - & - \\
$5 \%$ DMSO & - & - & - & - \\
\hline
\end{tabular}

*Diameter of zone of inhibition is expressed as mean \pm SD in $\mathrm{mm}$

\begin{abstract}
Minimum inhibitory concentration (MIC) and minimum fungicidal concentration (MFC) of solvent extract

The MIC values of the butanol extract of $P$. insolitus and $C$. oceanosedimentum were $250 \mu \mathrm{g} / \mathrm{mL}$ and $500 \mu \mathrm{g} / \mathrm{mL}$, respectively. The butanol extract had MFC values of 500 and $1000 \mu \mathrm{g} / \mathrm{mL}$ against $C$. albicans KACC 30062 and C. glabrata KBNO6P00368, respectively (Table 3).
\end{abstract}

\title{
PHYLOGENETIC TREE ANALYSIS OF IDENTIFIED BACTERIA
}

The isolated EB sequence were identified using 16S rRNA gene sequencing, aligned and the neighbor joining tree was constructed. The phylogenetic analysis of the $16 \mathrm{~S}$ rRNA of the two EB EAL86 and EAL157, isolated from E. arvense that exhibited highest anticandidal activity against $C$. albicans and $C$. glabrata revealed that these isolates correspond to two different species of Psychrobacillus and Curtobacterium respectively (Figure 5 ) .

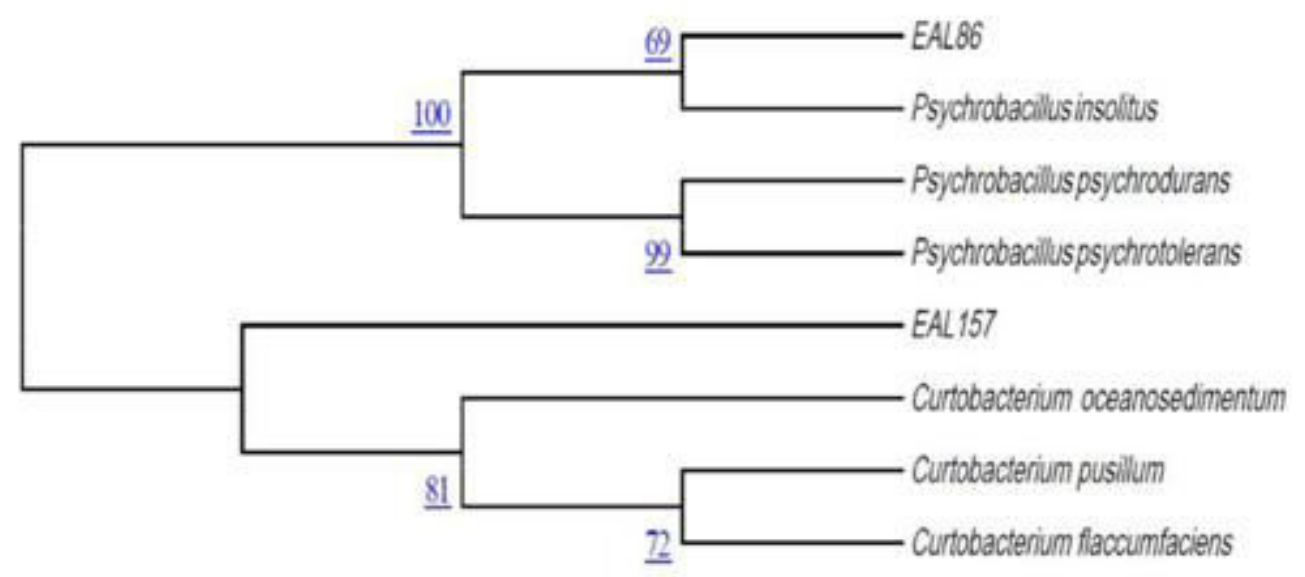

Figure 5: The phylogenetic relationship between the two endophytic bacteria $P$. insolitus (EAL86) and $C$. oceanosedimentum (EAL157) based on 16S rRNA sequences by the maximum likelihood method, performed using 1000 bootstrap replicates. Numbers above each node are confidence levels (\%) generated from 1000 bootstrap trees correspond to the scale bar of branch lengths (0.02).

\section{SEM ANALYSIS}

SEM analysis was carried out to visualize the effects of solvent extract on the morphology of C. albicans and C. glabrata after treatment with butanol extract at its MIC concentrations. SEM analysis revealed altered morphology of tested pathogenic 
Candida strains. Specifically, the control morphology was smooth, with a regular oval shape, while the treated strains showed rough, irregular shape, with swelling, cell bursting and much less density than the control (Figure 6).

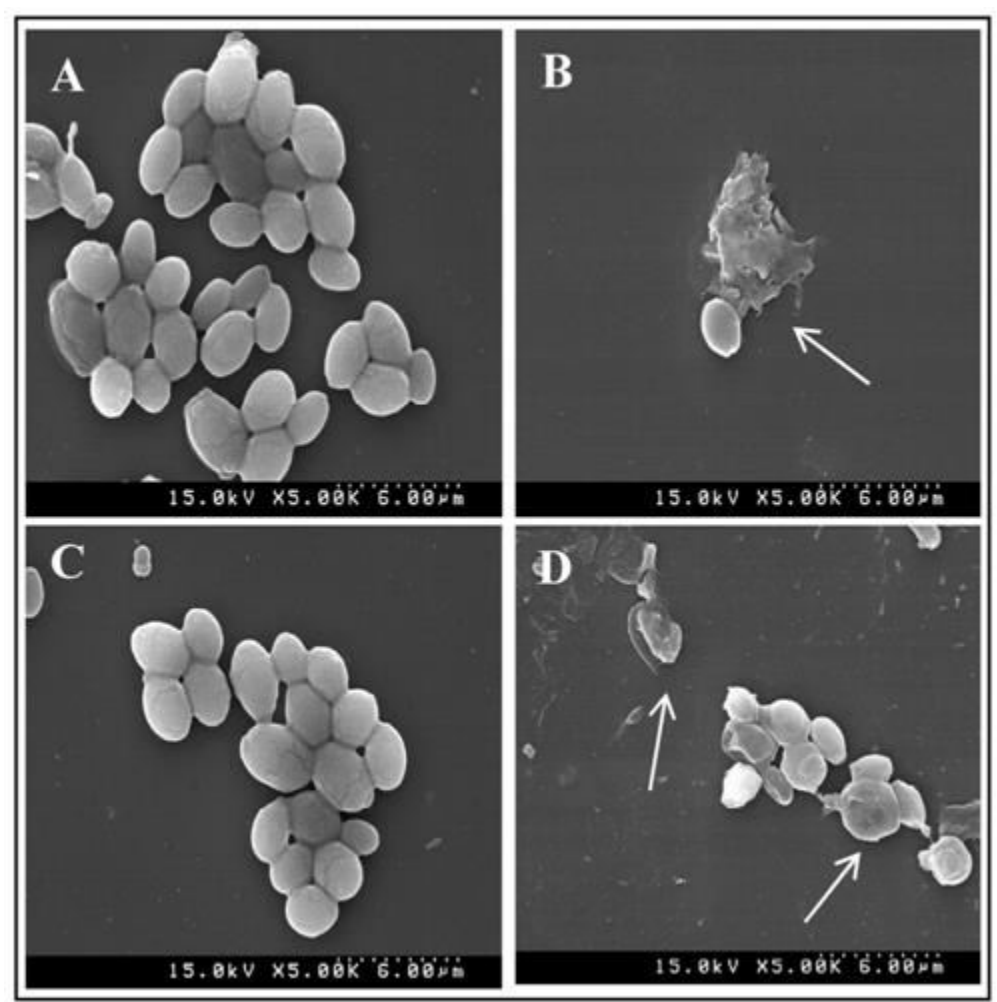

Figure 6: SEM analysis showing the effects of the butanol fraction on the morphology of (A) C. albicans KACC 30062 treated with 5\% DMSO; (B) C. albicans KACC 30062 treated with the butanol fraction of $P$. insolitus at the MIC; (C) C. glabrata KBNO6P00368 treated with 5\% DMSO; (D) C. glabrata KBNO6P00368 treated with the butanol fraction of $C$. oceanosedimentum at the MIC.

\section{DISCUSSION}

Candidiasis has re-emerged with higher prevalence and mortality rates of nearly $45 \%$ in compromised population groups ${ }^{46-48}$. In human Candida can cause life threatening systemic infections ${ }^{49}$. Moreover, clinicians have been challenged by the failure of standard antifungal agents. Consequently, there is an urgent requirement for novel anticandidal agents for management of Candida infection ${ }^{50}$. Microbial agents can be an appropriate replacement for artificial fungicides ${ }^{51}$ and EB are known to produce various types of active compounds with different biological activities; therefore, they are strong candidates for sources of novel antifungal agents ${ }^{20}$. In this study, EB with different shapes, sizes, colors and elevations were isolated from $E$. arvense (Figure 1, Figure 2) and identified using 16S rRNA gene sequencing (Table 1). Ten EB showed potential activity against C. albicans KACC 30003, C. albicans KACC 30062 and $C$. glabrata KBNO6P00368 (Table 2, Figure 3).

Above 200 genera of endophytic bacteria have been isolated from a huge diversity of plants all through the past years ${ }^{52}$. Many EB produce diverse compounds with special biological activities ${ }^{53,54}$. B. weihenstephanensis and S. ureolyticus were shown to only be active against $C$. albicans KACC 30003, while seven endophytic bacteria showed positive effects against $C$. albicans KACC 30062, and $C$. oceanosedimentum was effective against C. glabrata KBNO6P00368 (Table 2, Figure 3). Five of the identified EB were Bacillus species (Table 1). Bacillus species 
have been reported to be useful as bio-control agents against plant fungal diseases ${ }^{53}$. Numerous species of the Bacillus genus are reasonably considerable for the purposes, as they are functional for the production of numerous molecules and supplementary goods for foodstuff as well as in agricultural, biological and pharmaceutical industries ${ }^{55,56}$. In the pharmaceutical industry, there is high demand for Bacillus species because of its potential to produce a broad array of metabolites with antimicrobial activity ${ }^{57-61}$. Thus, the endophytic bacterias from $E$ arvense, including Bacillus sp., could potentially be useful for pharmaceutical industries. $P$. insolitus and A. oxydans showed strong activity against $C$. albicans KACC 30062, but $P$. insolitus showed the clearest and highest inhibition.

$P$. insolitus and $C$. oceanosedimentum showed the highest controlling effect against C. albicans and C. glabarata, respectively, and were therefore selected for solvent fractionation. The butanol extract of $P$. insolitus and $C$. oceanosedimentum inhibited the growth of $C$. albicans and $C$. glabarata (Table 3, Figure 4); however, the other fractions did not show any activity. The inhibition activity of the butanol extract is comparatively higher than that of the amphotericin $b$, which was taken as the reference standard. The phylogenetic tree construction was done using identified sequence of two selected EB. The neighbor joining tree was the evidence that these two bacteria belong to two different species and EAL 86, EAL157 are the closest relative of $P$. insolitus and $C$. oceanosedimentum respectively (Figure 5). These findings indicated that both EB secreted are active compounds, with high hydrophobic properties. SEM analysis clearly indicated that the Candida species had damaged and irregular cell morphology following treatment with butanol extracts of $P$. insolitus and C. oceanosedimentum at the MIC (Figure 6), indicating that the bioactive compounds contained in the butanol fraction lysed cell walls and destroyed cell membrane integrity ${ }^{5}$. Our current SEM results are in conformity with the studies of ${ }^{62 \text { and } 63}$.

Previous reports indicated that the two identified EB, $P$. insolitus and $C$. oceanosedimentum, would contain higher biological activities in addition to the anticandidal activity ${ }^{15}$. 64 . Therefore, these species were tested for various biological activities to determine the active compounds responsible for the anticandidal activity. The extract and essential oil of E. arvense had anticandidal activity against pathogenic Candida strains ${ }^{21,26,32,36}$. This activity of $E$. arvense might have been due to the presence of bioactive compounds produced by the plant itself; however, more sophisticated studies are required to verify the compound production by the endophytic bacteria inside the plant tissues.

\section{CONCLUSIONS}

The current study demonstrated that 10 identified endophytic bacteria isolated from $E$. arvense contained potential anticandidal activity against three pathogenic Candida species. P. insolitus and C. oceanosedimentum exerted strong anticandidal activities against $C$. albicans and $C$. glabarata, respectively, and were therefore selected for subsequent analyses. Successive fractionation using different solvents revealed that the active components of the bacteria were not antifungal proteins, but natural products. Moreover, the buatanolic fraction contained the active compounds. Overall, these findings indicate that endophytic bacteria isolated from E. arvense can serve as valuable resources in the search for natural anticandidal agents, and have the potential for use as substitutes for artificial fungicides to control candidiasis.

\section{ACKNOWLEDGEMENTS}


This work was carried out with the support of "Cooperative Research Program for Agriculture Science \& Technology Development (Project No. PJ010934)”, Rural Development Administration, Republic of Korea.

\section{REFERENCES}

1. Brilhante RSN, Caetano EP, Oliveira JS, Castelo-Branco DSCM, Souza ERY, Alencar LP, et al. Simvastatin inhibits planktonic cells and biofilms of Candida and Cryptococcus species. Brazilian J Infect Dis. 2015; 19 (5): 459-465.

2. Pfaller MA, Diekema DJ, Procop GW, Rinaldi MG. Multicenter comparison of the VITEK 2 antifungal susceptibility test with the CLSI broth microdilution reference method for testing amphotericin B, flucytosine, and voriconazole against Candida sp. J Clinic Microbiol. 2007; 45 (11): 3522-3528.

3. Sardi JCO, Scorzoni L, Bernardi T, Fusco-Almeida AM, Giannini MJSM. Candida species: current epidemiology, pathogenicity, biofilm formation, natural antifungal products and new therapeutic options. J Med Microbiol. 2013; 62: 10-24.

4. Kosikowska P, Pikula M, Langa P, Trzonkowski P, Obuchowski M, Lesner A. Synthesis and evaluation of biological activity of antimicrobial-pro-proliferative peptide conjugates. PLoS ONE. 2015; 10(10):1-16.

5. Bajpai VK, Kang SC, Kim S, Hasan MM, Dhakal R, Park E, Baek KH. Microbial conversion of tomato by Pectobacterium carotovorum subsp. carotovorum 21: a biotechnological approach to control pathogenic Candida species. Rom Biotech Lett. 2012; 17 (1): 6989-6998.

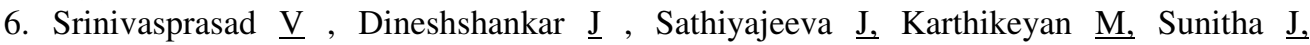
Ragunathan R. Liaison between micro-organisms and oral cancer. J Pharm Bioallied Sci. 2015; 7:354-360.

7. Singh-Babak SD, Babak T, Diezmann S, Hill JA, Xie JL, Chen YL et al. Global analysis of the evolution and mechanism of echinocandin resistance in Candida glabrat. PLoS Patho; 8 (5): 1-23.

8. Bodey GPMD, Mardani MMD, Hanna HAMD, Boktour MPHMMD, Abbas JMD, Girgawy EMD et al. The epidemiology of Candida glabrata and Candida albicans fungemia in immune compromised patients with cancer. American J Med. 2002; 112 (5): 380-385.

9. Horn DL, Neofytos D, Anaissie EJ, Fishman JA, Steinbach WJ, Olyaei AJ et al. Epidemiology and outcomes of candidemia in 2019 patients: data from the prospective antifungal therapy alliance registry. Clin Infect Dis. 2009; 48 (12): 1695 -1703.

10. Howard SJ, Livermore J, Sharp A, Goodwin J, Gregson L, Alastruey-Izquierdo A et al. Pharmacodynamics of Echinocandins against Candida glabrata: requirement for dosage escalation to achieve maximal antifungal activity in neutropenic hosts. Antimicrob Agents Ch. 2011; 55(10): 4880-4887.

11. Yenn TW, Lee CC, Ibrahim D, Zakaria L. Enhancement of anti-candidal activity of endophytic fungus Phomopsis sp. ED2, isolated from Orthosiphon stamineus Benth, by incorporation of host plant extract in culture medium. J Microbiol. 2012; 50 (4): 581-585.

12. Ho H, Haynes K. Candida glabrata: new tools and technologies-expanding the toolkit. FEMS Yeast Res. 2015; 15:1-14.

13. Yadav M, Yadav A, Kumar S, Sharma D, Yadav JP. Evaluation of in vitro antimicrobial potential of endophytic fungi isolated from Eugenia jambolana Lam. Inter J Pharm Pharmac Sci. 2014; 6 (5): 208-211.

14. Achkar JM, Bettina CF. Candida infections of the genitourinary tract. Clin Microbiol Rev. 2010; 23(2): 253-273.

15. Audipudi AV, Allu S, Pradeep KN, Chowdappa P. Plant growth promoting potential of a novel endophytic Curtobacterium CEG: Isolation, evaluation and formulation. Annals Biolog Res. 2014; 5 (5):15-21.

16. F. Rezzonico, T.H.M. Smits, E. Montesinos, J.E. Frey, and B. Duffy, "Genotypic comparison of Pantoea agglomerans plant and clinical strains," BMC Microbiology, vol. 9, pp. 1-18, 2009. 
17. Chellaram C. Screening of Antagonistic Endophytic bacteria from Phyllanthus niruri leaves. Int J Pharm Tech Res. 2015; 8(2): 230-234.

18. Roh E, Lee S, Lee Y, Dongsu R, Choi J, Moon E, Heu S. Diverse antibacterial activity of Pectobacterium carotovorum subsp. carotovorum isolated in Korea. J Microbiol Biotechn. 2009; 19 (1): 42-50.

19. Tabbene O, Kalai L, Ben SI, Karkouch I, Elkahoui S, Gharbi A, Cosette P, Mangoni ML, Jouenne T, Limam F. Anti-candida effect of Bacillomycin D-like lipopeptides from Bacillus subtilis B38. FEMS Microbiol Lett. 2011; 316(2): 108 -114.

20. Bhoonobtong A, Sawadsitang S, Sodngam S, Mongkolthanaruk W. Characterization of endophytic bacteria, Bacillus amyloliquefaciens for antimicrobial agents production. International Conference on Biological and Life Sciences, IPCBEE, Singapore, 23rd to 24th July, Singapore, 2012.

21. Kukric Z, Topalic-Trivunovic L, Pavicic S, Zabic M, Matos S, Davidovic A. Total phenolic content, antioxidant and antimicrobial activity of Equisetum arvense. Chem Ind Chem Eng Q. 2013; 19(1): 37-43.

22. Geetha RV, Lakshmi T, Roy A. In vitro evaluation of anti-bacterial activity of Equisetum arvense linn on urinary tract pathogens. Int J Pham Pharmace Sci. 2011a; 3 (4): 323-325.

23. Sandhu NS, Kaur S, Chopra D. Equisetum arvense: pharmacology and photochemistry - a review. Asian J Pharmace Clin Res. 2010; 3(3): 146-150.

24. Canadanovic-Brunet JM, Cetkovic GS, Djilas SM, Tumbas VT, Savatovic SS, Mandic AI, Markov SL, Cvetkovic DD. Radical scavenging and antimicrobial activity of horsetail (Equisetum arvense L.) extracts. Int J Food Sci Tech. 2009; 44: 269-278.

25. Alexandru V, Petrusca DN, Gille E. Investigation of pro-apoptotic activity of Equisetum arvense water extract on human leukemia U 937 cells. Rom Biotech Lett. 2007;12/2: 3139 3148 .

26. Radulovic N, Stojanovic G, Palic R. Composition and antimicrobial activity of Equisetum arvense L. essential oil. Phytother Res.2006; 20(1): 85-88.

27. Kumar A, Kaushik P. Antibacterial effect of Equisetum arvense L. Asian J Biol Sci. 2011; 6: 184-187.

28. Geetha RV, Roy A, Lakshmi T. Nature's weapon against urinary tract infections. Int J Drug Development Res. 2011b; 3(3): 85-100.

29. Ceyhan N, Keskin D, Ugur A. Antimicrobial activities of different extracts of eight plant species from four different family against some pathogenic microorganisms. J Food Agric Envir. 2012; 10(1): 193-197.

30. Sinha SN. In vitro antibacterial activity of ethanolic extract of Equisetum arvense L. Int J Pharma Bioll Res. 2012; 3(1): 19-21.

31. Oliveira JRD, Almeida RBDA, Grac P, Vilela F, Rocha RF, Jorge AOC et al. Control of microorganisms of oral health interest with Arctium lappa L. (burdock) extract non cytotoxic to cell culture of macrophages (RAW 264.7). Arch Oral Biol. 2014; 59 (8): 808814.

32. Tepe B, Donmez E, Unlu M, Candan F, Dafererad D, Vardar-Unlu G et al. Antimicrobial and antioxidative activities of the essential oils and methanol extracts of Salvia cryptantha (Montbret et Aucher ex Benth.) and Salvia multicaulis (Vahl). Food Chem. 2004; 84: 519525.

33. Leifert C, Li H, Chidburee S, Hampson S, Workman S, Sigee D, Epton HA, Harbour A. Antibiotic production and biocontrol activity by Bacillus subtilis CL27 and Bacillus pumilus CL45. J Appl Bacteriol. 1995; 78 (2): 97-108.

34. S.S. Pattnaik, J. Bapaji, and C.R. Kole, "Antibacterial and antifungal activity of aromatic constituents of essential oils," Microbiology, vol. 89, no. 358, pp. 39-46, 1997.

35. Cvetkovic DJ, Stanojevic LP, Kundakovic T, Zlatkovic SZ, Nikolic GS. Antioxidant and antimicrobial activity of a new generation phyto-gel. Advanced Technologies. 2015; 4 (2): 11-18.

36. Oliveira JR, Castro VC, Vilela PGF, Camargo SEA, Carvalho CAT, Antonio JOC et al. Cytotoxicity of Brazilian plant extracts against oral microorganisms of interest to dentistry. BMC Complem Altern M. 2013; 13(208): 1-7. 
37. Uslu ME, Erdogan I, Bayraktar O, Ates M. Optimization of extraction conditions for active components in Equisetum. Rom Biotech Lett. 2013; 18 (2): 8115-8131.

38. Costa LEO, Marisa VQ, Borges AC, Moraes CA, Araujo EF. Isolation and characterization of endophytic bacteria isolated from the leaves of the common bean (Phaseolus vulgaris). Braz J Microbiol. 2012; 43 (4): 1562-1575.

39. Khanam B, Chandra R. Isolation and identification of endophytic bacteria producing bright red pigment from the dye yielding plant Beta vulgaris L. Int J Pharm Pharma Sci. 2015; 7 (5): 220-224.

40. Ngoma L, Mogatlanyane K, Babalola OO. Screening of endophytic bacteria towards the development of cottage industry: an in vitro study. J Hum Ecol. 2014; 47 (1): 45-63.

41. Zubair M, Rizwan K, Rasool N, Afshan N, Shahid M, Ahmed VD. Antimicrobial potential of various extract and fractions of leaves of Solanum nigrum. Int J Phytomed. 2011; 3 (1): 63-67.

42. Diao WR, Hu QP, Feng SS, Li WQ, Xu JG. Chemical composition and antibacterial activity of the essential oil from green huajiao (Zanthoxylum schinifolium) against selected foodborne pathogens. $J$ Agr Food Chem. 2013; 61(25): 6044-6049.

43. Kubo I, Fujita K, Kubo A, Nihei K, Ogura T. Antibacterial activity of coriander volatile compounds against Salmonella choleraesuis. J Agr Food Chem. 2004; 52 (11): 29-32.

44. Susilowati R, Sabdono A, Widowati I. Isolation and characterization of bacteria associated with brown algae Sargassum spp. from Panjang Island and their antibacterial activities. Procedia Environ Sci. 2015; 23: 240-246.

45. BajpaVK, Shukla S, Kang SC. Chemical composition and antifungal activity of essential oil and various extract of Silene armeria $L$. Bioresource Technol. 2009; 99 (18): 8903-8908.

46. Wenzel RP, Gennings C. Bloodstream infections due to Candida species in the intensive care unit: identifying especially high-risk patients to determine prevention strategies. Clin Infect Dis. 2005; 41: 389-393.

47. Yan Z, Hua H, Xu H, Samaranayake LP. Potent antifungal activity of pure compounds from traditional Chinese medicine extracts against six oral Candida species and the synergy with fluconazole against azole-resistant Candida albicans. Evidence- Based Complement Altern M. 2012; 2012: 1-6.

48. Srinivasprasad V, Dineshshankar J , Sathiyajeeva J, Karthikeyan M, Sunitha J, Ragunathan R. Liaison between micro-organisms and oral cancer. J Pharm Bioallied Sci. 2015; 7:354-360.

49. Seneviratne CJ, Rajan S, Wong SSW, Tsang DNC, Lai CKC, Samaranayake LP, Jin L. Antifungal susceptibility in serum and virulence determinants of candida bloodstream isolates from Hong Kong. Front Microbiol. 2016; 7: 1-8.

50. Haque F, Alfatah M, Ganesan K, Bhattacharyya M S. Inhibitory effect of sophorolipid on candida albicans biofilm formation and hyphal growth. Sci Rep. 2016; 6: 1-11.

51. You-Jin Y, Yu-sheng L, Bo X, Wen-ping L, Pang L, Zhi-dan T. Optimization of medium composition and culture conditions for antifungal activity of a tomato endophytic bacterium. Biol Control. 2015; 82: 69-75.

52. Tian BY, Cao Y, Zhang KQ. Metagenomic insights into communities, functions of endophytes, and their associates with infection by root-knot nematode, Meloidogyne incognita, in tomato roots. Sci Rep. 2015; 5: 1-15. 
53. Souza A, Cruz JC, Sousa NR, Procopio ARL, Silva GF. Endophytic bacteria from banana cultivars and their antifungal activity. Genet Mol Res. 2014; 13 (4): 8661-8670.

54. Idramsa, Soetarto ES, Nugroho LH, Pratiwi R. Antimicrobial activities of endophytic bacteria isolated from Cotylelobium melanoxylon (hook.f.) pierre. Int J Pharm Bio Sci. 2016; 7(2): 666-672.

55. Alavarce RAS, Saldanha LL, Almeida NLM, Porto VC, Dokkedal AL, Lara VS. The beneficial effect of Equisetum giganteum L. against Candida biofilm formation: new approaches to denture stomatitis. Evidence-Based Complement Altern M. 2015; 2015:1-9.

56. Yamashiro D, Yoshioka M, Ashiuchi M. Bacillus subtilis pgsE (Formerly ywtC) stimulates poly- $\gamma$-glutamate production in the presence of zinc. Biotechnol Bioeng. 2011; 108(1): 226-230.

57. Silo-Suh LA, Lethbridge BJ, Raffel SJ, He H, Clardy J, Handelsman J. Biological activities of two fungistatic antibiotics produced by Bacillus cereus UW85. Appl Environ Microb. 1994; 60(6): 2023-2030.

58. Waites MJ, Morgan NL, Rockey JS, Higton M. Industrial Microbiology an Introduction. Blackwell Publisher, London. 2001; 30-32.

59. Huang J, Du Y, Xu G, Zhang H, Zhu F, Huang L, Xu Z. High yield and cost-effective production of poly(c-glutamic acid) with Bacillus subtilis. Eng Life Sci. 2011; 11 (3): 291297.

60. Amin JN, Batool M, Mahmoud MA. Screening antibacterial and antifungal activities and evaluation of the exhaustive extractions yields for Verbascum sinuatum L. Int J Res Ayurved Pharma. 2015; 6(1): 105-110.

61. Sumi CD, Yang BW, Yeo IC, Hahm YT. Antimicrobial peptides of the genus Bacillus: a new era for antibiotics. Can J Microbiol. 2015; 61: 93-103.

62. Nurkanto A, Julistiono H. Screening and study of antifungal activity of leaf litter actinomycetes isolated from Ternate Island, Indonesia. Asian Pac J Trop Med. 2014; 7:238243.

63. Sharma P, Kalita MC, Thakur D. Broad spectrum antimicrobial activity of forest-derived soil Actinomycete, Nocardia sp. PB-52. Front Microbiol. 2016; 7:1-17.

64. Pham VHT, Jeong SW, Kim J. Psychrobacillus soli sp. nov., capable of degrading oil, isolated from oil-contaminated soil. Int J System Evol Microb. 2015; 65 (9): 3046-3052. 


\section{Erratum}

In Article "Anticandidal effect of endophytic bacteria isolated from Equisetum arvense L. against Candida albicans and Candida glabrata", with the number of DOI: http://dx.doi.org/10.1590/1678-4324-2017160433, publish in journal Brazilian Archives of Biology and Technology, vol. 60, the page 1.

that read:

Gitishree Das $^{1 *}$, Jayanta Kumar Patra ${ }^{2}$, Nurul Islam ${ }^{1}$, Kwang-Hyun Baek ${ }^{1}$

${ }^{l}$ Yeungnam University - Biotechnology, Korea; ${ }^{2}$ Dongguk University - Research Institute of Biotchnology Ilsandong, Korea.

read:

Gitishree Das ${ }^{1}$, Jayanta Kumar Patra ${ }^{1}$, Jaehyuk Choi ${ }^{2}$, Kwang-Hyun Baek ${ }^{2 *}$.

${ }^{1}$ Dongguk University - Seoul, Research Institute of Biotchnology \& Medical Converged Science, Goyang-si, South Korea; ${ }^{2}$ Yeungnam University, Department of Biotechnology, Gyeongsan, South Korea. 